\title{
Application of Knowledge Visualization in the Teaching and Learning of Higher Vocational College Network Courses
}

\author{
Fangzheng Wang* \\ Yancheng Vocational Institute of Health Science, Yancheng Jiangsu 224005, China \\ 41437160@qq.com
}

\begin{abstract}
The article herein may analyze the network courses of higher vocational college first, starting from the teaching and learning status quo. And then the article may elaborate the necessity of knowledge visualization in the teaching and learning of network courses of higher vocational college. Meanwhile integrating features of students in higher vocational colleges, the paper may analyze several ways of visualization in the teaching and learning of network courses and explore them deeper in the process, which may make the visualization technology work sufficiently in the teaching and learning of network courses.
\end{abstract}

Keywords: Knowledge Visualization, Higher Vocational College, Teaching and Learning of Network Courses.

\section{Introduction}

Knowledge visualization will be formed basing on the visualization of data and information. However, knowledge visualization is different from the visualization of date and information and they are essentially distinct. The knowledge visualization technology mentioned in the paper may refer to the transmission and updating of group knowledge by means of the utilization of visual representation from its definition and study the effect of visual representation which may enable knowledge to be transmitted and updated among groups. Moreover, its ultimate goal is to accomplish transmission of opinions, experience, attitudes, values, expectation, views, pieces of advice and prediction and to assist others to reconstruct, memorize and apply the knowledge correctly at the same time.

\section{The Necessity of the Application of Knowledge Visualization in the Higher Vocational Network Courses}

With the progress of era, computer technology and network technique have been increasingly booming especially for some majors related to computer, which has already regarded the basic principles of network as the necessity of learning set in the course. And for higher vocational college students, there are several situations of the learning of network courses, which will showed as followed: firstly, the knowledge in the network courses is not only abundant but also shares large span; secondly, it might be hard to understand the basic principles of the network and the basic techniques are also difficult, which will be tough for students to memorize ; thirdly, students in higher vocational college may lack learning foundation, which may let them fear of learning especially for some kinds of textual knowledge including the concept and principle of the network. They even aren't patient enough to learn network techniques and skills. Meanwhile there are also some problems happening to the teaching and learning of higher vocational network courses which include:

(1) Teachers are expected to explain some knowledge clearly in the limited time including the definition and principle of computer network. Moreover, teachers may are preferred to choose some ways of teaching suitable for higher vocational college students, which may be hard to realized in some extent. Sometimes teachers themselves may have problems in teaching difficulty.

(2) There may be not sufficient teaching materials provided exclusively for higher vocational college students. 
(3) Colleges are short of funds and equipments to establish computer network laboratories, which may hinder the learning of students especially for the grasp of the principle and skill of computer network.

According to the problems of the teaching in higher vocational college network courses mentioned above, there should be some teaching methods to arouse the enthusiasm of students and improve the teaching efficiency in the meantime. People try hard to find the ways of teaching to reach the goal. After deeply studying, we find the importance of knowledge visualization and its effect when introduced into the teaching and learning of network courses, which may eventually ease the problems mentioned above and point out the significant meaning of knowledge visualization ${ }^{[1]}$.

In the field of education, knowledge visualization is a direction of application to realize knowledge-based engineering techniques. Meanwhile, in the field of educational technology, this kind of technology that demands more of knowledge engineering and boosts the development of educational technology will be applied first in order to the accomplishment of the application of knowledge engineering. Nowadays teachers all apply the knowledge visualization technique in the teaching of various subjects actively, which has already made the teaching activities so successful and led to great effects of teaching and learning. For example, it will make students easily understand barometric change and the distribution of the geological by applying the knowledge visualization technique when teaching geography and science; in the teaching of physics, making full use of the knowledge visualization technique can help simulate shock wave, eddy and electromagnetic field; and moreover, in the teaching of chemistry, the application of the technique can definitely demonstrate molecular structure and chemical reaction; in the teaching of computer and science, the technique can also analyze data structure and operating system. Generally speaking, all the subjects mentioned above have been taught in the assistance of the visualization technique. To make use of visual representation to show these abstract, complicated and intricate concepts and principles based on the application of the technique may make students grasp the knowledge easily and eventually fulfill teaching goals ${ }^{[2]}$.

\section{Application of Knowledge Visualization in the Higher Vocational College Network Courses}

\subsection{Use Concept Map Visualization Network Knowledge}

Targeting at the higher vocational college network courses, in the special process of teaching and learning, there might be some knowledge involved comparison and teachers always use concept map to describe the knowledge to students when teaching these content. For example, concept map could be used to explain the network reference models such as ISO/OSI and TCP/IP, which may let students comprehend the definition and function of network layer and know the two network reference models and their necessity well. Moreover, concept map is able to be used to describe the details of the processes of experiments in order that students can understand how to make use of ports to the partition of VLAN, which may finally show the whole steps of the experiment to students and deepen the understanding of theoretical knowledge in the process.

\subsection{Use Mind Map to Reconstruct the Network Concept System}

According to the modern study theory, for a learner, the construction of knowledge is based on the connection of new concepts and the knowledge mastered. And the so-called mind map refers that maps established by nodes and lines are used to illustrate the relations between concepts, which will be utilized to figure out the connections between concepts. Finally the knowledge system and structure will be showed evidently through the map especially in the part of the layers and structure of knowledge. For higher vocational college network courses, there are plenty of fundamental concepts and theories during the teaching and learning which are always both the core and difficult part of learning. And sometimes there are also complicated connections among these concepts, which may make the learning part especially harsh. Since the utilization of concept visualization technique, it has helped students to comprehend the concepts that they couldn't understand before by means of the integration of figures, which may make their structures clear and easy for students to grasp. 
In a word, the mind map can actively be used to describe a network concept, a kind of network equipment or even a kind of network technology and it can also be used to show hierarchy. For example, if we set VLAN as the core to develop a mind map, which will be showed in figure one. It will be truly easy for students to master the related knowledge of VLAN based on the map. Additionally teachers can integrate the features of teaching contents and prepare the courseware that is to say brainstorming software, thus students can grasp the structure of knowledge clearly and end up learning with enthusiasm.

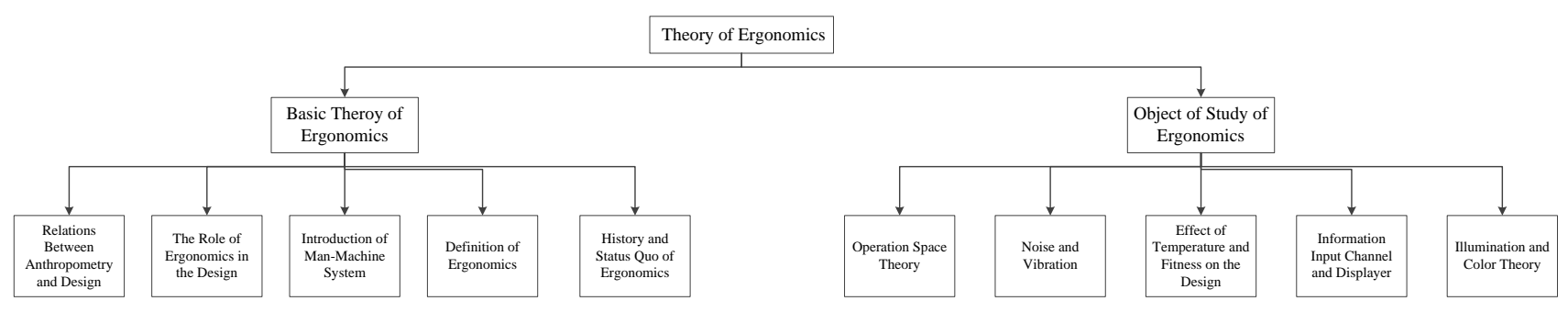

Fig. 1 Mind Map of VLAN

For computer network courses, the mind map can also play an important role in improving the performance of teaching and learning including: firstly, students can reconstruct knowledge systems by themselves; secondly, students can learn further about details of knowledge; thirdly, it can help the interaction between teachers and students by means of the principle of brainstorming and the abilities of discussion and collaboration of students' can be improved at the same time.

\subsection{Visualize Abstract Theories by Means of Animation}

Some problems can be hard to describe because of their complexity. It is when presentation can be used to understand things. Targeting at higher vocational college network courses, there might be some unintelligible knowledge in the process of teaching and learning when two-dimensional and three-dimensional animation can be used to show students such as fiber splicing technology which may be hard to describe only by words and dictation, but students can easily understand that when using the form of animation as showed in figure 2.

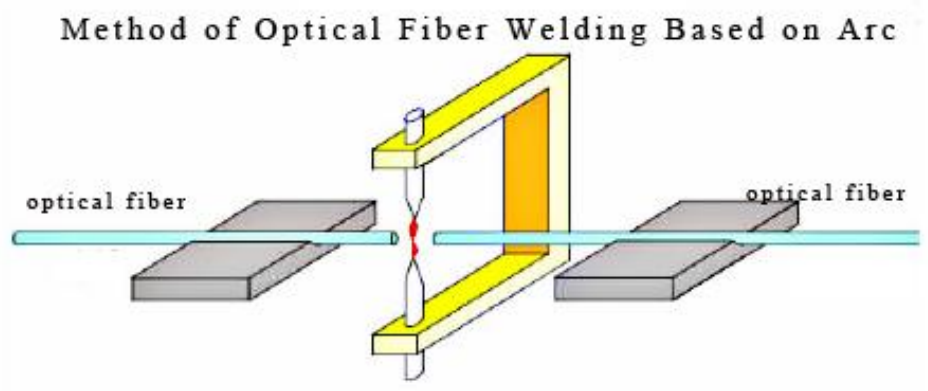

Fig.2 Animation Diagram of Fiber Splicing by Arc Method

\subsection{Use Simulation Software as the Tool of Visualization to Deepen Students' Understanding and Application of Network Knowledge}

The operating principles of network technologies are also abstract. If teachers give lectures only by words, it may be hard for students to understand the whole process. For example, there might be problems of what the WEB servers, routers and switches can do and how they function. So in fact, the virtual machine software and the router and switches simulation software should be used to help students and stimulate their interest.

At present, there are several kinds of virtual machine software such as VMware workstation and Virtu-al PC and the router and switches simulation software like Bosom, Dynamips, Pac and ket Tracer. However, what can be used in the teaching and learning of network courses will be Pack-et Tracer or VMware workstation + Dynamip. In a word, the simulation software should play an 
important role in the teaching and learning in order to enhance students' understanding of how network equipments function.

\section{Conclusion}

Generally speaking, knowledge visualization technology should be introduced into the teaching and learning in order that students can fully understand and grasp some abstract theories and complicated practices. Students' initiative and creativity are highly improved since the utilization of the mind map in practical teaching, which may make students master knowledge much more easily and form good study habits to enhance their non-specialized qualities.

\section{Acknowledgements}

We acknowledge the support of Jiangsu University Philosophy and Social Science Research Fund guidance project and Research on the Application of Knowledge Visualization in Computer Course of Higher Vocational Education (2014SJD704).

\section{References}

[1] Epperson J. Effects of the Use of Dynamic Visualization on Inservice Teachers and Graduate Students Content Knowledge and Pedagogical Content Knowledge of Transformations of Functions $[\mathrm{C}] / /$ Society for Advancement of Hispanics/chicanos and Native Americans in Science National Conference. 2013.

[2] Mingyong Z. Investigation into the use of mobile technology in English teaching and learning in institutes of higher vocational education in Hubei province in China[C]// International Conference on Futuristic Trends on Computational Analysis and Knowledge Management. IEEE, 2015. 